IRSTI $30.51 .23 ; 30.17 .35 ; 28.17 .23$

\author{
${ }^{1 *}$ A.S. Askarova, ${ }^{1}$ S.A. Bolegenova, ${ }^{1}$ S. A. Bolegenova, \\ ${ }^{1}$ V.U. Maximov, ${ }^{1}$ A.O. Nugymanova, ${ }^{2}$ P. Safarik \\ ${ }^{1}$ Faculty of physics and technology, al-Farabi Kazakh National University, Almaty, Kazakhstan \\ ${ }^{2}$ Faculty of mechanical engineering, Technical University in Prague, Prague, Greece \\ "e-mail: aizhana0708@mail.ru

\section{Combustion processes in furnace chambers of Kazakhstan TPPs using high-ash coal}

\begin{abstract}
In this article, carried out computational experiments to study the aerodynamic, thermal and concentration characteristics in combustion chamber of the boiler BKZ-420 Almaty TPP-2. Combustion chamber BKZ-420 has a significant drawback, which is that of a jet of hot air hitting the wall that is opposite the burners. This leads to her firing and a further violation of integrity. On the Almaty CHP-2 in the basic mode using this wall served cold the air mass flow $5 \mathrm{~kg} / \mathrm{s}$. In this paper, we proposed a new flow mode, which allows you to protect the wall from overheating, to reduce the temperature of the incoming flow more cold air. Carried out researches have allowed to conclude that the proposed regime provides not only protection against overheating of the boiler walls, but also reduces the concentration of harmful emissions. As a result of computer experiments were obtained fields of velocity, temperature, concentrations of harmful dust and gas emissions $(\mathrm{CO}, \mathrm{CO} 2, \mathrm{NO} 2)$ formed in combustion of solid fuels for different layout options holes and speed boost-extra air $(5 \mathrm{~kg} / \mathrm{s}$ and $10 \mathrm{~kg} / \mathrm{s})$.
\end{abstract}

Key words: numerical simulation, combustion chamber, temperature, air velocity, carbon dioxide, nitrogen dioxide.

\section{Introduction}

The main consumer of primary energy resources in Kazakhstan is the electricity and heat generation sector (about $50 \%$ of consumed fuel). The total capacity of power generating sources in the RK is more than 18 thousand MW. The basis of generating capacity is thermal power plants - about $87 \%$. The main type of fuel and energy resources in Kazakhstan is coal, the supply of which is mainly from the Ekibastuz field. Burning fossil fuels to produce electrical energy and heat, especially the power industry, with its huge centralized power plants, is one of the foundations of the functioning of a modern society and economy. On the other hand, fuelburning installations consume large amounts of fossil fuel of different types, converting them into useful energy. The functioning of these enterprises leads to the formation of a variety of waste and delivery of large quantities of contaminants in all natural environments.

In recent decades, the rapid growth in computing power and the continuous improvement of numerical algorithms has led to the extension of the range of applications available for study by computational methods. This increases the requirements to the mathematical models describing a certain class of application tasks, and accuracy of numerical methods for their implementation.

Relevant in the present time is the study of heat and mass transfer processes in industrial power plants, in particular, heating devices, thermal power plants operating on solid fuel. The goal of environmentally sound and efficient use of coal fuel to nominate important issues for research in this area. The solution to the problem of reducing harmful emissions of thermal power plants requires the development of new designs and optimization of operating modes of furnaces, and in General - development of scientific bases of creating ecologically clean thermal power plants for solid fuels. At the same time, physical modeling of real combustion processes or full-scale tests on boilers is characterized by extremely high cost. Consideration of modern thermal and environmental requirements in solving problems of development of perspective and modernization of existing designs of

Printed in Kazakhstan 
furnace facilities and optimization of their operating modes requires at present the attraction of numerical simulation methods for the comprehensive study of furnace processes.

However, the formation of complexes (packages) computer programs, sufficiently accurate and versatile to conduct serial numerical experiment on modeling of the totality of the combustion process, remains an urgent task.

\section{Experimental part}

As object of research was selected combustion chamber of the boiler BKZ-420, with steam capacity $420 \mathrm{t} / \mathrm{h}$, located at the Almaty CHP-2. The boiler BKZ-420-140-7 designed to work on the Ekibastuz coal for generation of superheated steam in thermal power plants with cogeneration turbines with high steam parameters. Scheme of the combustion chamber of the boiler and its breakdown into control volumes is shown in figure 1, and the input data used in conducting computational experiments are summarized in table 1.

The combustion chamber of the boiler (figure 2) is equipped with six-vortex flow of the two pulverized coal burners arranged in two levels with three burners on the front wall of the boiler. Extreme burner is turned to the center of the furnace by 8 degrees. The capacity of one burner is $12 \mathrm{t} / \mathrm{h}$ of Ekibastuz coal. In the furnace burned dust lowgrade high-ash Ekibastuz coal ash content $40 \%$, a volatiles $24 \%$, moisture $5 \%$ and the highest calorific value of $16.750 \mathrm{~kJ} / \mathrm{kg}$. Fineness of grinding of coal was equal to $\mathrm{R} 90=15 \%$. All numerical calculations were performed on the above-mentioned technique [1-7].

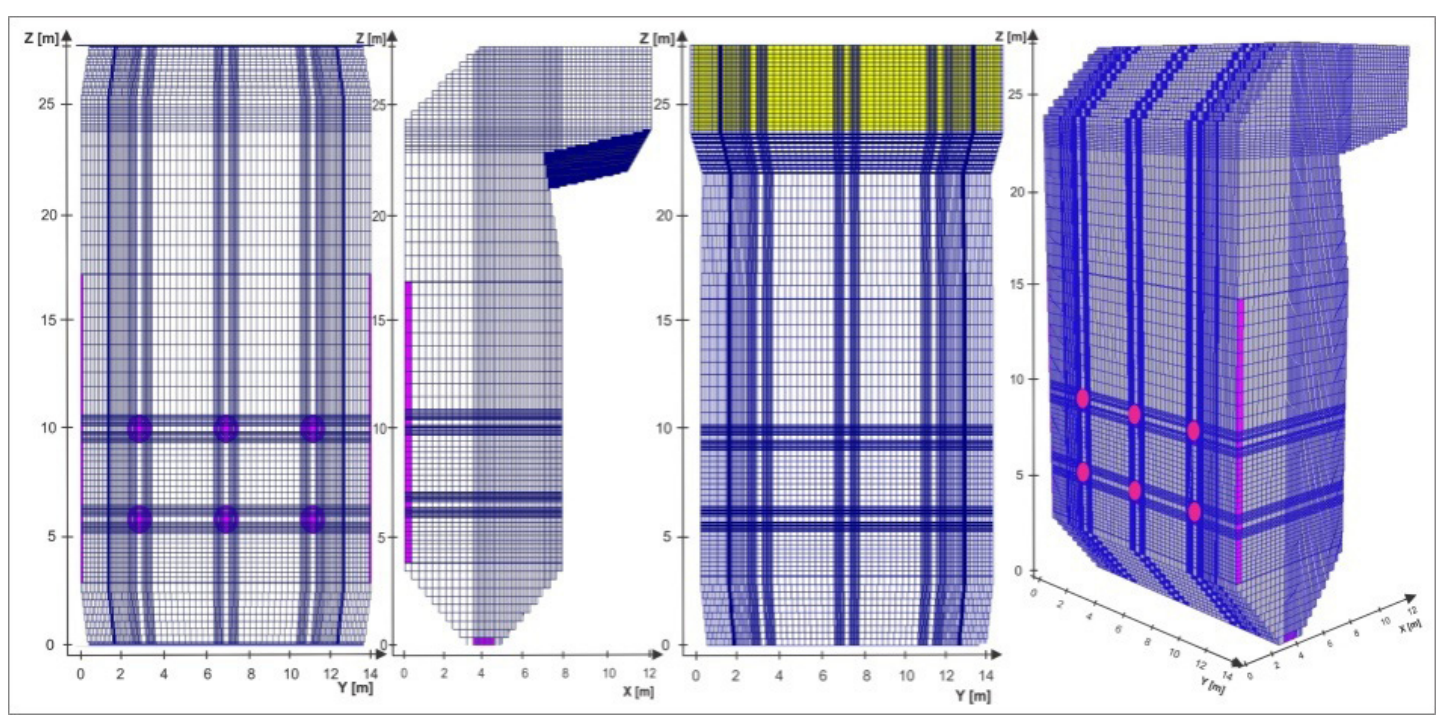

Figure 1 - General view of the combustion chamber

of the boiler BKZ-420 Almaty TPP-2 and its breakdown into control volumes

Table 1 - Technical characteristics of the boiler BKZ-420 and input data for numerical simulation

\begin{tabular}{|l|l|c|c|c|}
\hline № & \multicolumn{1}{|c|}{ Name } & Designation & Size & Meaning \\
\hline & Humidity & $\mathrm{W}_{\mathrm{r}}$ & $\%$ & 5 \\
\hline & Ash & $\mathrm{A}_{\mathrm{r}}$ & $\%$ & 40.0 \\
\hline & The lowest calorific value & $\mathrm{Q}_{\mathrm{r}}$ & $\mathrm{kcal} / \mathrm{kg}$ & 4000 \\
\hline & Devolatilization & $\mathrm{V}_{\text {daf }}$ & $\%$ & $24-28$ \\
\hline & Sulfur & $\mathrm{S}_{\mathrm{t}}$ & $\%$ & $0.4-0.7$ \\
\hline \multicolumn{2}{|c|}{ The elemental composition of the fuel mass } \\
\hline
\end{tabular}


Continuation of Table 1

\begin{tabular}{|c|c|c|c|}
\hline Nitrogen & $\mathrm{N}_{\text {daf }}$ & $\%$ & 1.5 \\
\hline Oxygen & $\mathrm{O}_{\text {daf }}$ & $\%$ & 11.5 \\
\hline The number of boilers at thermal power plants & $\mathrm{N}_{\mathrm{B}}$ & pieces & 7 \\
\hline One of the kindling according to the regulations & $\mathrm{t}$ & hour & $3.5 \div 4$ \\
\hline Fuel consumption for the boiler (at full load) & $\mathrm{B}$ & th & 72 \\
\hline Type burners & \multicolumn{3}{|c|}{ Vortex dual stream } \\
\hline The number of burners in the boiler & $\mathrm{N}_{\mathrm{B}}$ & pieces & 6 \\
\hline The performance of one of the burner fuel & $\mathrm{B}_{\mathrm{B}}$ & th & 12 \\
\hline The temperature of Aero mixture after mills & $\mathrm{t}_{\mathrm{a}} / \mathrm{cm}$ & ${ }^{\circ} \mathrm{C}$ & $90 \div 130$ \\
\hline The primary air flow per burner (two separate channels) & $\mathrm{V}_{\text {P.B. }}$ & $\mathrm{Nm}^{3} / \mathrm{h} * 10^{3}$ & $13860(17879.4 \mathrm{~kg} / \mathrm{h})$ \\
\hline The flow of secondary air to the burner (two channels) & $\mathrm{V}_{\mathrm{S}^{* B}}$ & $\mathrm{Nm}^{3} / \mathrm{h} * 10^{3}$ & $52140(67260.6 \mathrm{~kg} / \mathrm{h})$ \\
\hline The temperature of hot air & $\mathrm{T}_{\text {H.A. }}$ & ${ }^{\circ} \mathrm{C}$ & $280 \div 340$ \\
\hline The coefficient of excess air for furnace & $\alpha_{F}$ & & $1.1 \div 1.4$ \\
\hline
\end{tabular}

\section{Results and discussion}

This paper presents results of 3-D modeling of Ekibastuz coal burning in furnace of boiler BKZ420 Almaty TPP-2 for two variants of the flow of additional air through the holes located on the opposite wall burners and is shown in figure 2 .

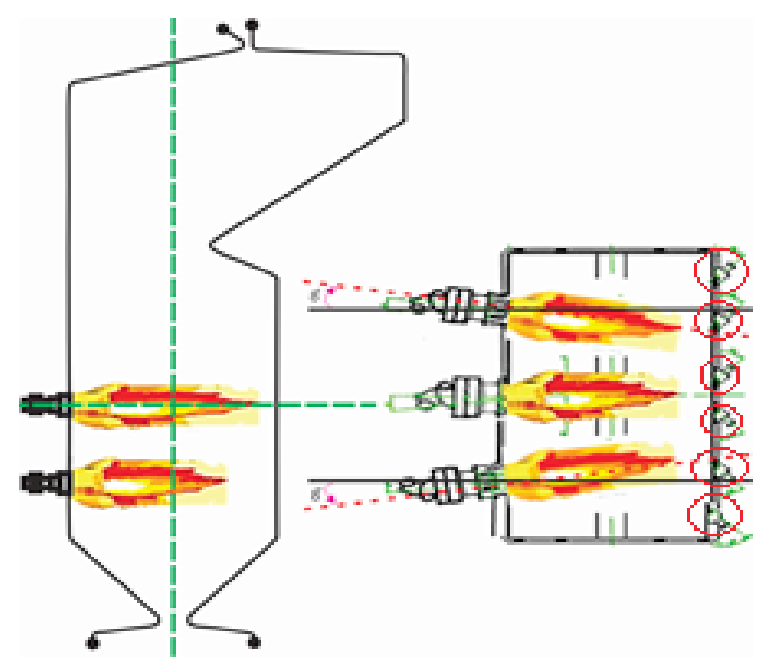

Figure 2 - General view of the industrial boiler BKZ-420 Almaty TPP-2

The burning of fuel at the Almaty TPP -2 is carried out when the value of the mass air flow 5 $\mathrm{kg} / \mathrm{s}$ through the holes in the wall of the combustion chamber located opposite the burner (see Fig. 2). In the course of research work we have proposed a new mode of operation for CHP-2, when the flow rate is doubled, and the holes are located at an angle of $45^{\circ}$ to the wall of the boiler. The choice of angle of $45^{\circ}$ creates the condition for the formation of the arc stream, which protects the walls from overheating and helps to reduce the temperature of the return flow.

As a result of computational experiments on the aerodynamics of the process was constructed of the distribution of the vector full speed, which are shown in figures 3-5.

Figure 3 shows the distribution of the vector of full speed in the longitudinal section $(\mathrm{y}=7.18 \mathrm{~m})$ of the boiler BKZ-420 at a mass flow equal to $5 \mathrm{~kg} / \mathrm{s}$ (figure $3 \mathrm{a}$ ) and $10 \mathrm{~kg} / \mathrm{s}$ (figure $3 \mathrm{~b}$ ) and directed from the wall opposite the burners.

Analyzing figure 3 , we see that the flows from the lower burners, colliding with the opposite wall, forming a return current. Part of the flow towards the cold region of the funnel forms the bottom of the vortex. Another part is directed upward to the region of the upper burners and openings for secondary air, which also generated turbulence. Maximum values of velocity is in the region of the pulverized coal burner secondary air.

Comparing figures 3 (a) and 3 (b), we note that with increasing mass flow of air from the anti-burners, increases the turbulence as well as maximum, average and minimum speed values. The maximum speed value for the first case is equal to $36.6 \mathrm{~m} / \mathrm{s}$, and the second $38 \mathrm{~m} / \mathrm{s}$ When the mass flow rate of air is 10 $\mathrm{kg} / \mathrm{s}$ flow of Aero mixture and air create turbulence above and below the upper burners. The formation of the turbulent eddies creates the best conditions for complete combustion of pulverized coal. 


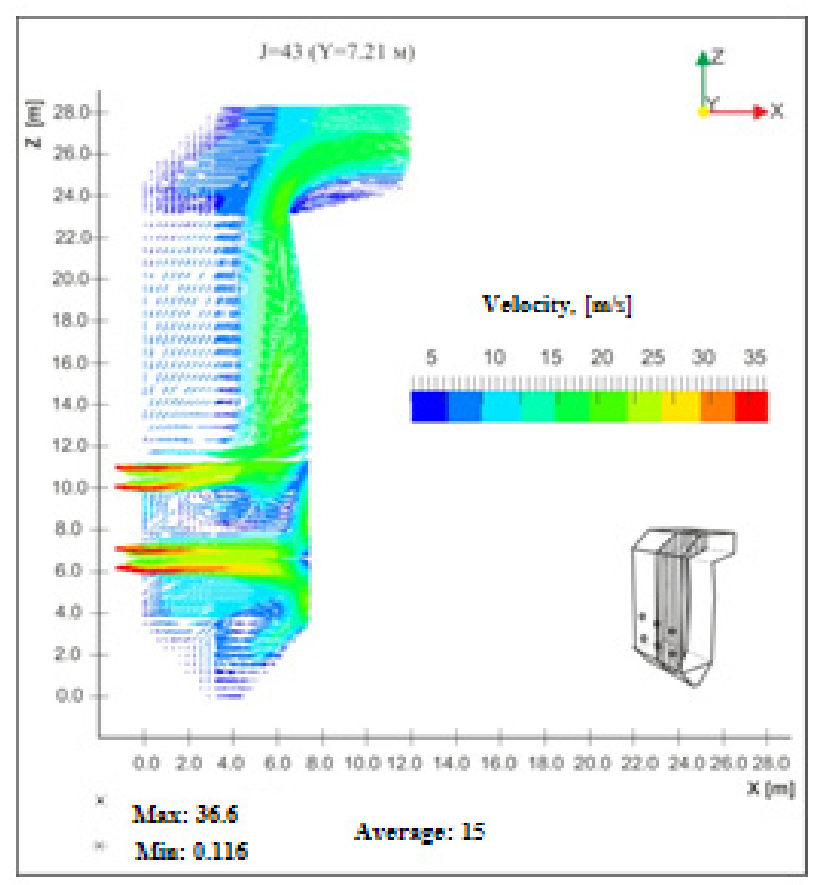

a) $5 \mathrm{~kg} / \mathrm{s}$

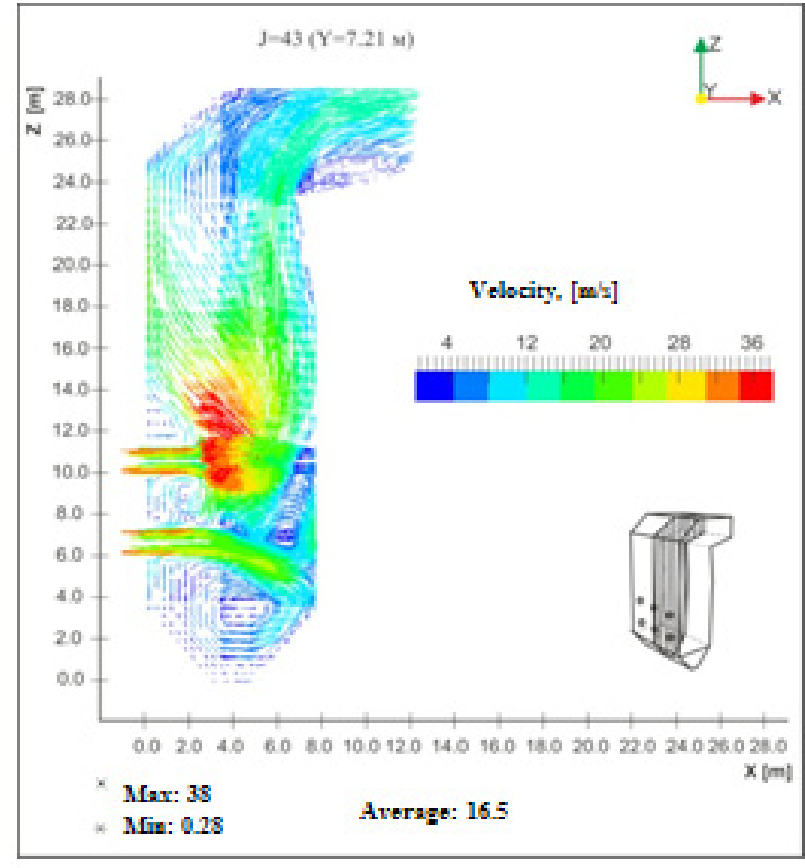

b) $10 \mathrm{~kg} / \mathrm{s}$

Figure 3 - Distribution of the vector of full speed in the Central longitudinal section $(\mathrm{y}=7.18 \mathrm{~m})$ of the combustion chamber of the boiler BKZ-420 Almaty TPP-2

Figure 4 ( $a$ and $b$ ) shows the distribution of the vector of full speed in the longitudinal section of the combustion chamber $(X=4 \mathrm{~m})$, located closer to the burners, for different values of the mass flow of air $(5 \mathrm{~kg}$ and $10 \mathrm{~kg}$ ). From the drawings it is seen that in each case at equal speeds of expiry of Aero mixture (coal dust+primary air) from the burner devices, counter flows collide and, due to the presence of the suction cups through the bottom hole in the lower part of the furnace and to form in the area of two longitudinal cold funnel of the vortex.

Formed in this region, the vortices create the conditions for uniform heating of the walls of the combustion chamber and solve the problem of slagging of furnace screens, which prolongs the service life of individual elements of the boiler plant and increases the surface of heat removal.

A large swirling flow in the Central region of the combustion chamber is beneficial to the combustion process of pulverized coal due to the turbulent nature of the flow, there is an intensive mixing of the propellant with the oxidant, and thus provides a more complete burnout of coal dust, and this in turn has to use larger fractions of coal particles.

The use of large fractions of the particles of pulverized coal reduces the cost of dust-preparation of coal, transportation and feeding it into the combustion chamber that is more cost-effective. In addition, such an arrangement of furnace processes (figures 3-4) eliminates the need for the installation of devices for the introduction of secondary air to assist combustion of the coal particles, which undoubtedly would have led to an increase in heat losses and increased formation of harmful dust and gas emissions from the combustion chamber into the atmosphere.

5-the figure shows the distribution of the full velocity at $6 \mathrm{~m}$ from the burner along the $\mathrm{X}$ axis or on the opposite wall from the area burners on $2 \mathrm{~m}$. one Can notice that the velocity values in figure 5 in comparison with its values in figure 4 . This is because of the holes on the burners on the opposite wall serves an additional stream of air with high velocity. Figure 5 (b), we see that the maximum speed is $80 \mathrm{~m} / \mathrm{s}$. This value 2 times greater than the rate in figure 5 (a).

5 -the figure shows the distribution of the full velocity at $6 \mathrm{~m}$ from the burner along the $\mathrm{X}$ axis or on the opposite wall from the area burners on $2 \mathrm{~m}$. one Can notice that the velocity values in figure 5 in comparison with its values in figure 4 . This is because of the holes on the burners on the opposite wall serves an additional stream of air with high velocity. Figure 5 (b), we see that the maximum speed is $80 \mathrm{~m} / \mathrm{s}$. This value 2 times greater than the rate in figure 5 (a). 


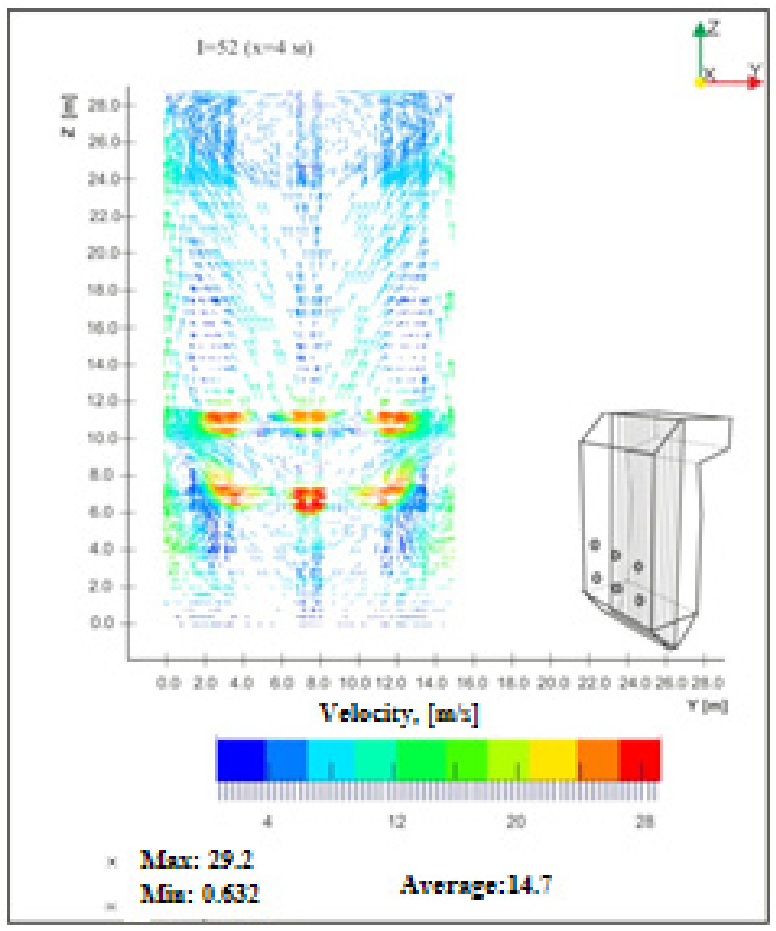

a) $5 \mathrm{~kg} / \mathrm{s}$

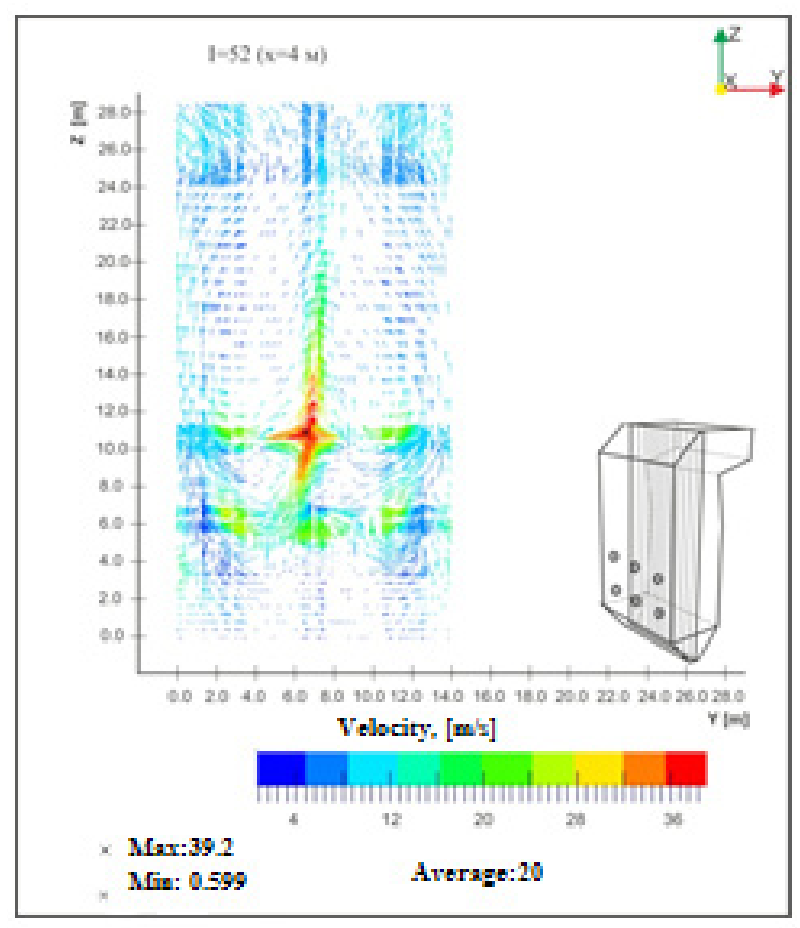

b) $10 \mathrm{~kg} / \mathrm{s}$

Figure 4 - Distribution of the vector of full speed in the center of the longitudinal sections of the combustion chamber $(\mathrm{X}=4 \mathrm{~m})$

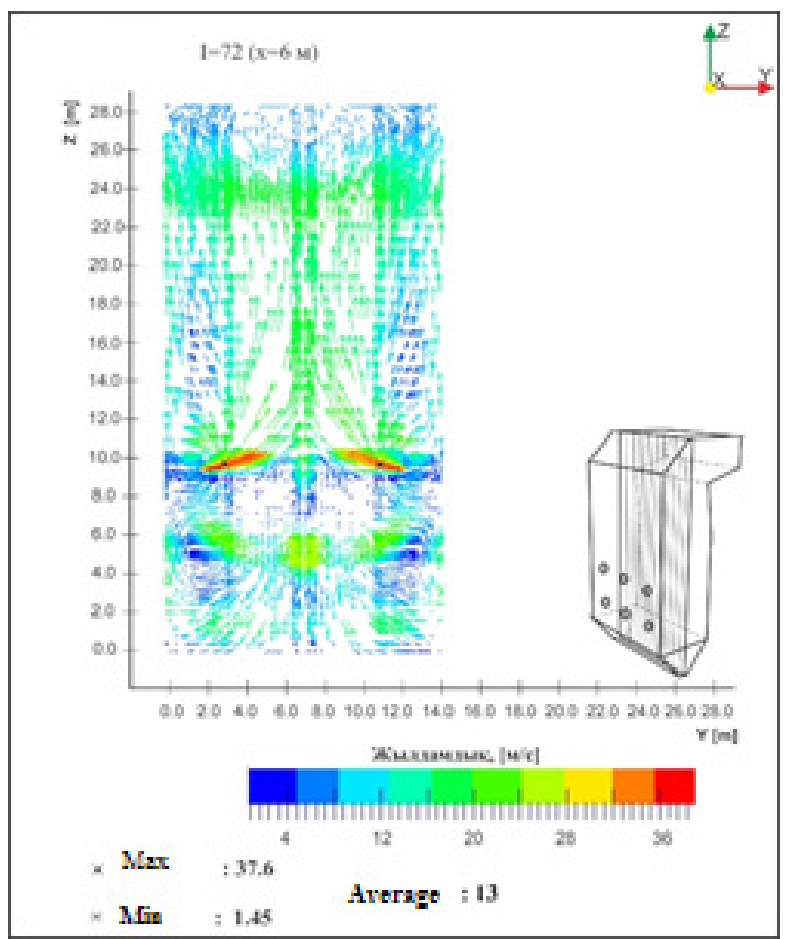

a) $5 \mathrm{~kg} / \mathrm{s}$

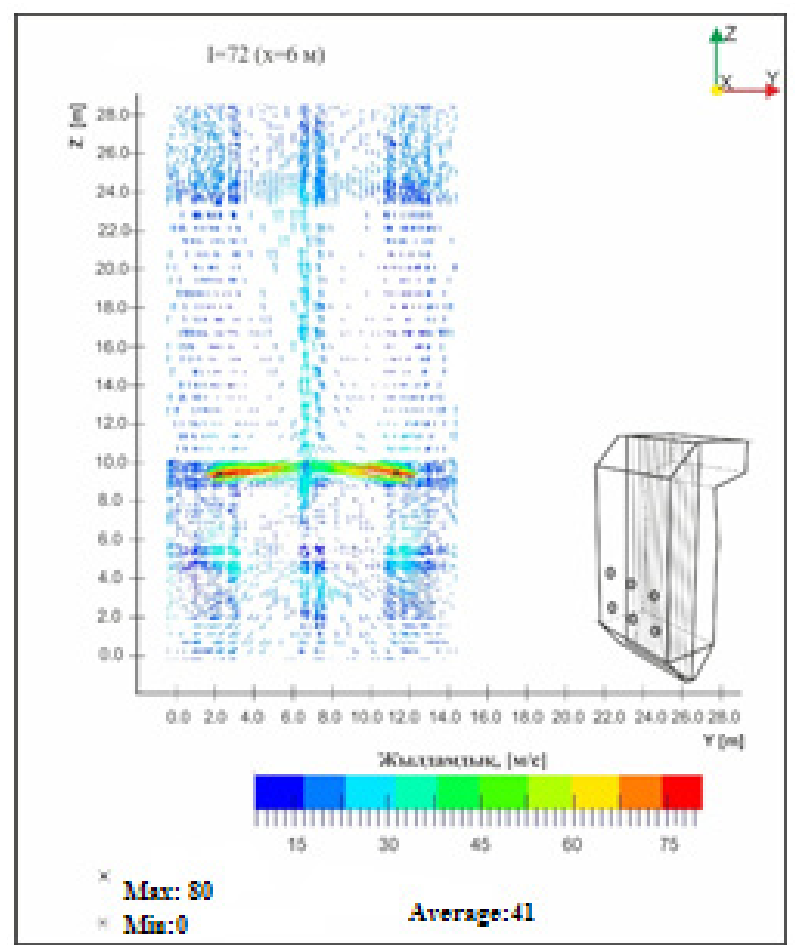

b) $10 \mathrm{~kg} / \mathrm{s}$

Figure 5 - Distribution of the vector full speed in the center of the longitudinal sections of the combustion chamber $(\mathrm{X}=6 \mathrm{~m})$

International Journal of Mathematics and Physics 8, №2, 51 (2017) 
Figure 6 shows a three-dimensional field of temperature distribution in two longitudinal sections $(\mathrm{Y} 1=2.95 \mathrm{~m}$ and $\mathrm{Y} 3=11.4775 \mathrm{~m})$ of the combustion chamber located in areas of extreme burners of the upper and lower tiers. We see that the flow of additional air, equal to $5 \mathrm{~kg} / \mathrm{s}$ maximum temperature is observed at the wall located opposite to the burners and is equal to $1740^{\circ} \mathrm{C}$ in the lower arusu burner $(\mathrm{Z}=6.82 \mathrm{~m})$. And at an air flow of $10 \mathrm{~kg} / \mathrm{s}$ (figure $6 \mathrm{~b}$ ) one can notice that the temperature at the wall has significantly decreased to about $350^{\circ} \mathrm{C}$.

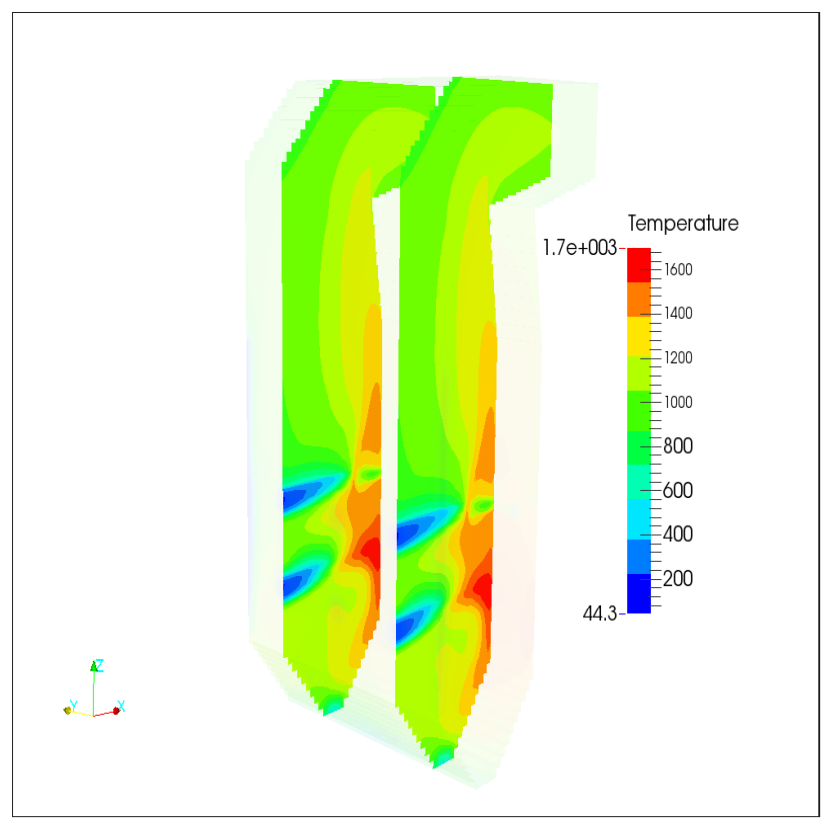

a) $5 \mathrm{~kg} / \mathrm{s}$

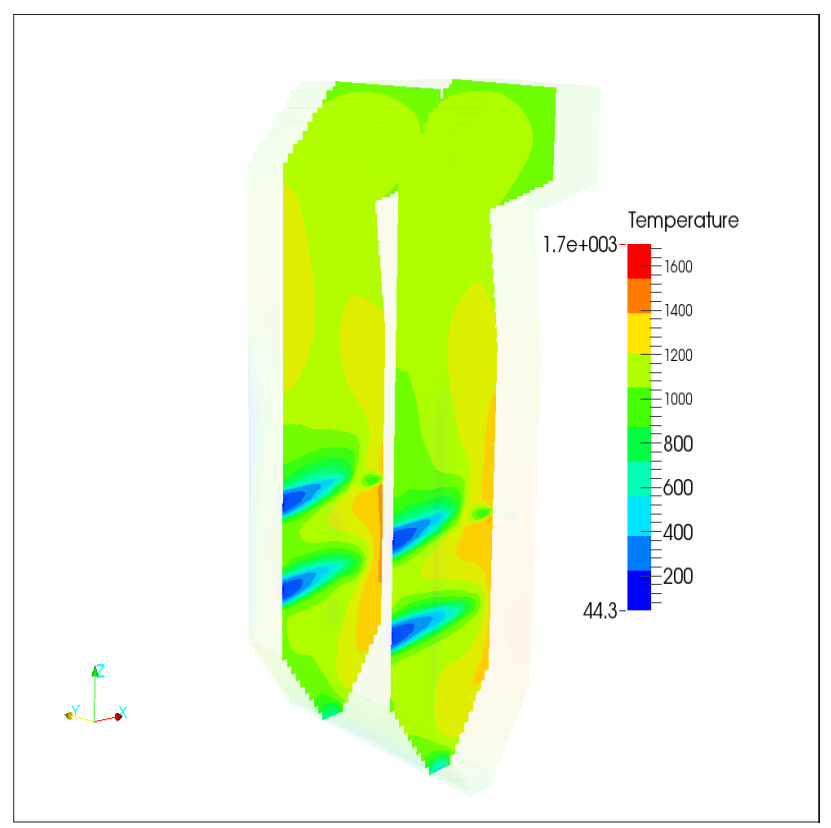

b) $10 \mathrm{~kg} / \mathrm{s}$

Figure 6 - Three-dimensional distribution of the temperature field in longitudinal cross-section $\mathrm{Y} 1=2.95 \mathrm{~m}$ and $\mathrm{Y} 3=\mathrm{m} 11.4775$ of the combustion chamber

Figure 7 shows the temperature distribution in the longitudinal section along the $X$-axis $(X=4.01$ $\mathrm{m})$. From the analysis of figure shows that at low mass flow rate of air $(5 \mathrm{~kg} / \mathrm{s})$ of counter burners torch is formed in a region between the burners (figure $7 \mathrm{a})$, while at higher flow rate $(10 \mathrm{~kg} / \mathrm{s})$ temperature field (figure $7 \mathrm{~b}$ ), as it were, in the sky, height of the furnace.

Figure 8 shows the temperature field at the outlet of the combustion space for the two values of the air flow from holes: $5 \mathrm{~kg} / \mathrm{s}$ and $10 \mathrm{~kg} / \mathrm{s}$. As can be seen from the drawings, in the second case (figure $8 \mathrm{~b}$ ) the area of high temperatures is less than in the first case (figure 8 a).

Since the burner and the holes for secondary air is installed on the opposite walls and directed towards each other, in the center of the furnace in the zone of contact flows, as mentioned earlier, the cut. Part of the flow goes into the area of the cold funnel, forming two longitudinal vortex at a height of below $10.8 \mathrm{~m}$ and the part formed by thrust, heading for the exit. Next, as you move to the exit of the furnace and chemical processes weaken (figure 6), the temperature falls and the output of its average value is $\sim 1045^{\circ} \mathrm{C}$ for flow rates of $5 \mathrm{~kg} / \mathrm{s}$ (figure $6 \mathrm{a}$ ) and $987^{\circ} \mathrm{C}$ - flow rate $10 \mathrm{~kg} / \mathrm{s}$ (figure $6 \mathrm{~b}$ ).

The above is confirmed by two-dimensional graphs of the temperature distribution along the height of combustion chamber for two different mass flows of additional air through the opening shown in figure 9. The analysis of the figure shows that at a height of $\mathrm{z}_{1}=6.82$ and $\mathrm{z}_{2}=10.8$ meters burner is pumped through the cold hole, there are minima in the temperature distribution. The output of the camera when the mass air flow $5 \mathrm{~kg} / \mathrm{s}$ temperature value higher than the supply at $10 \mathrm{~kg} / \mathrm{s}$. 


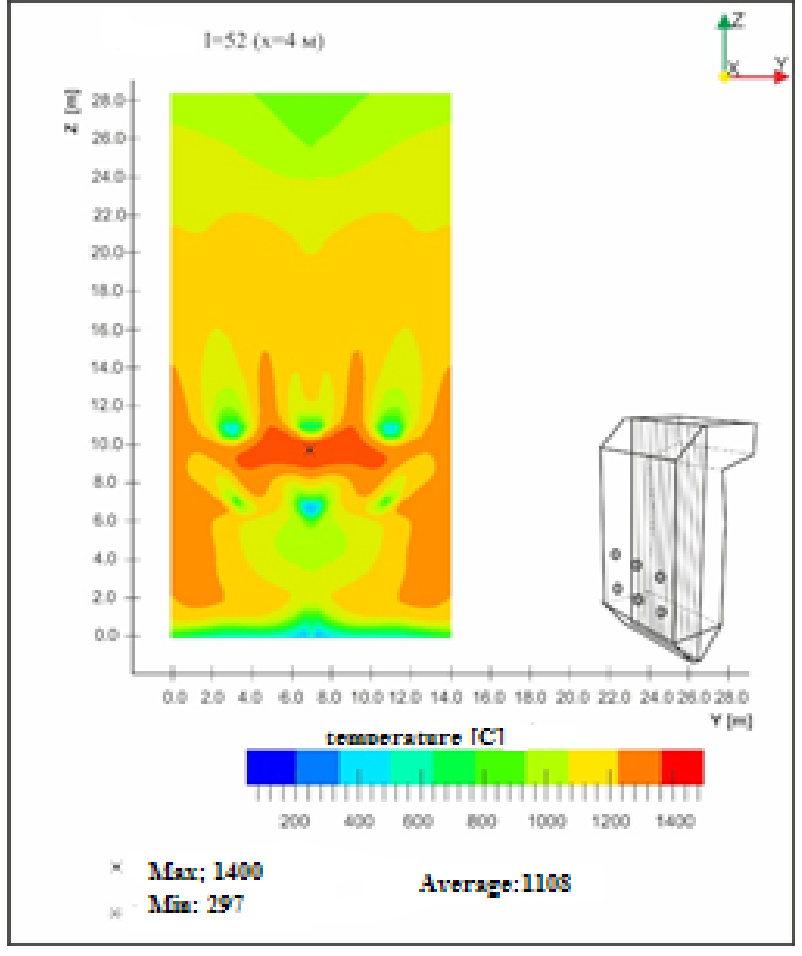

a) $5 \mathrm{~kg} / \mathrm{s}$

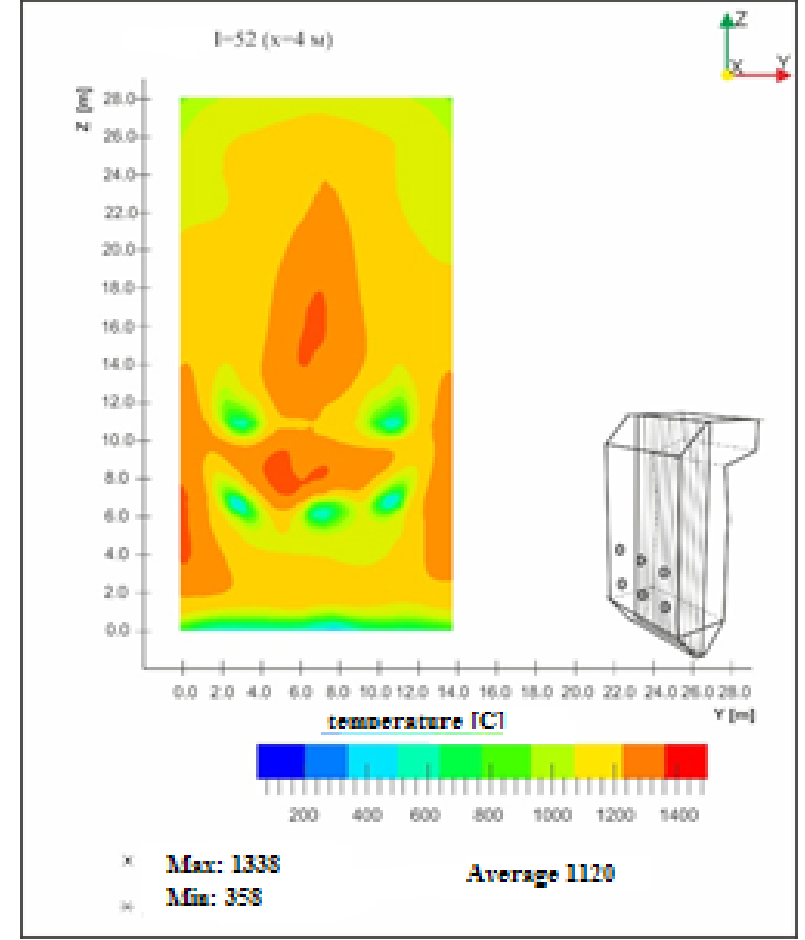

b) $10 \mathrm{~kg} / \mathrm{s}$

Figure 7 - Temperature field in longitudinal section of $X=4.01 \mathrm{~m}$ for different values of mass air flow

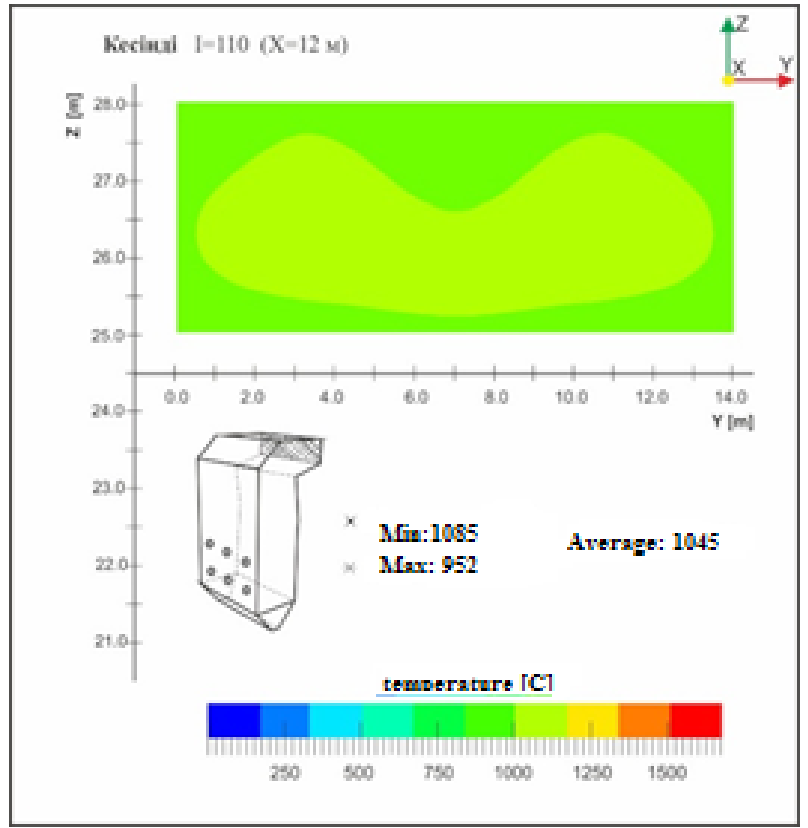

a) $5 \mathrm{~kg} / \mathrm{s}$

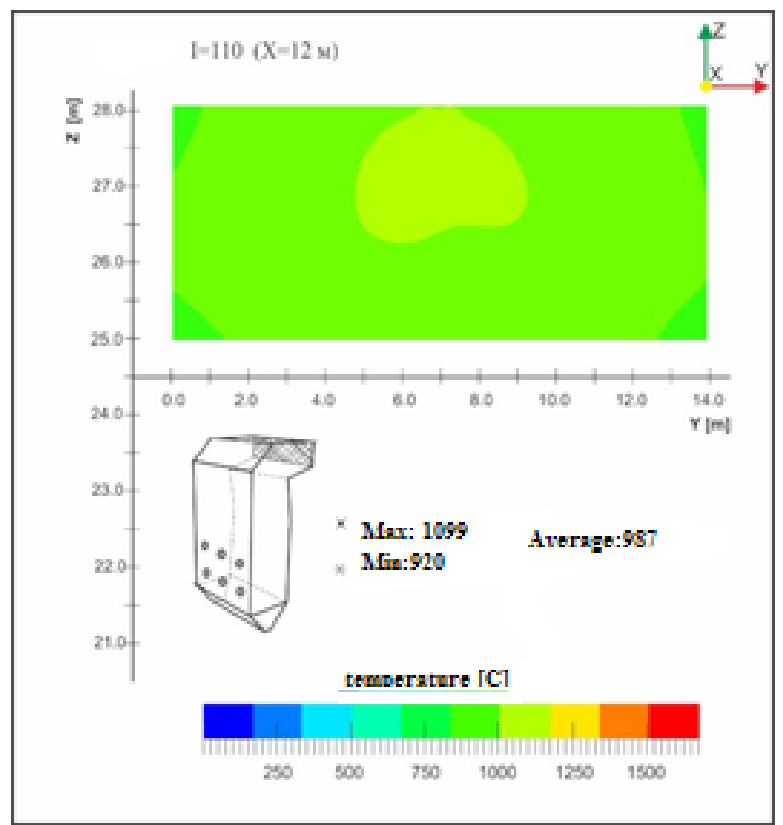

b) $10 \mathrm{~kg} / \mathrm{s}$

Figure 8 - Temperature field at the exit of combustion chamber $(\mathrm{X}=12 \mathrm{~m})$ 
This is because in this area are located the burner through which pulverized coal is supplied fuel and oxidizer at a temperature lower than the temperature of the camera. In the region of the belt burners are observed and the maximum temperature, because here is the core of the torch.

The outlet temperature of the furnace is supported by its experimental value $\left(\mathrm{T}=1171{ }^{\circ} \mathrm{C}\right)$, obtained directly in the CHP, are given in [8-10] and numerical [11]. Comparing these values, we can conclude: conducted a computational experiment to determine temperature in volume of the combustion chamber, with sufficient accuracy consistent with the measured values of temperature (figure 9). This allows you to judge the reliability of the obtained results and the applicability of physical, mathematical and numerical models to further study the thermal and concentration characteristics of combustion chamber BKZ 420 Almaty TPP-2 [12]. For more references, see [13]- [21].

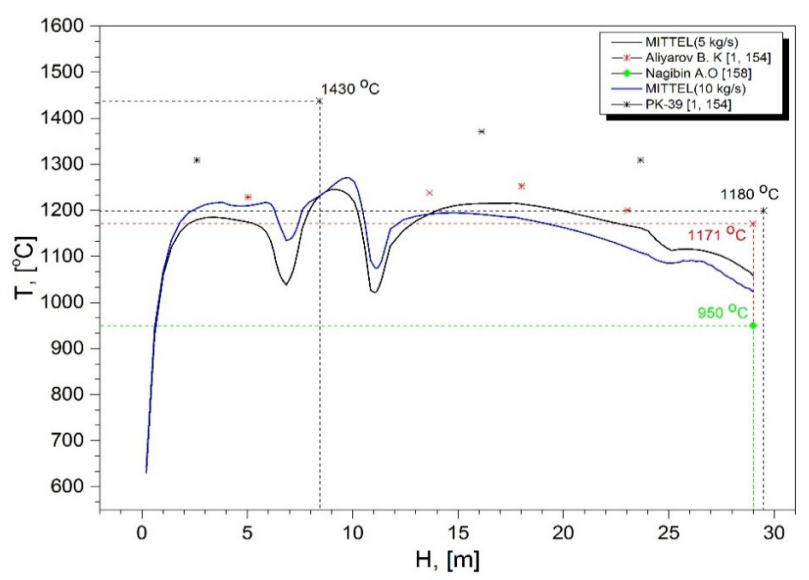

Figure 9 - Average temperature in the height of the boiler furnace

Figure 10 shows the distribution of average values of concentrations of carbon monoxide CO at the height of the furnace for two different values of the mass flow of additional air through the holes located on the opposite burner wall. We see that as a three-dimensional color graph of the temperature field at the exit of the combustion chamber at a mass flow equal to $5 \mathrm{~kg} / \mathrm{s}$, the concentration value of carbon monoxide $\mathrm{CO}$ higher in comparison with the case where the flow rate is $10 \mathrm{~kg} / \mathrm{s}$.

Analysis figure 10 shows that the maximum of both curves reach the region of the burners. This is because the largest concentrations coming into this part of the furnace carbon fuel and oxygen oxidizer, the intensity of physic-chemical interaction between them, causing here a strong increase in temperature and large heat release due to chemical reactions between the propellants and oxidizer.

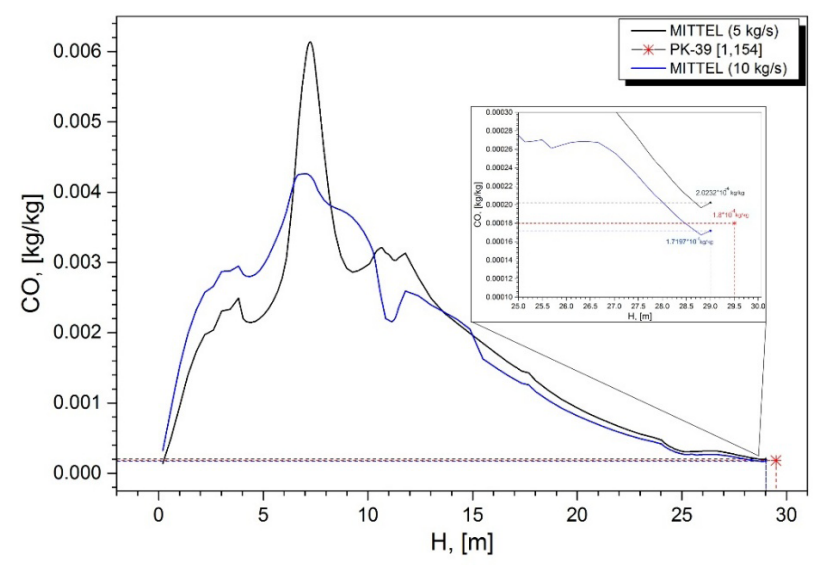

Figure 10 - distribution of the concentration of carbon monoxide $\mathrm{CO}$ at the height of the combustion chamber

Figure 11 shows a comparative graph of the distribution of average values of carbon dioxide $\mathrm{CO}_{2}$ the height of the combustion chamber for the two values of mass air flow $5 \mathrm{~kg} / \mathrm{s}$ and $10 \mathrm{~kg} / \mathrm{s}$.

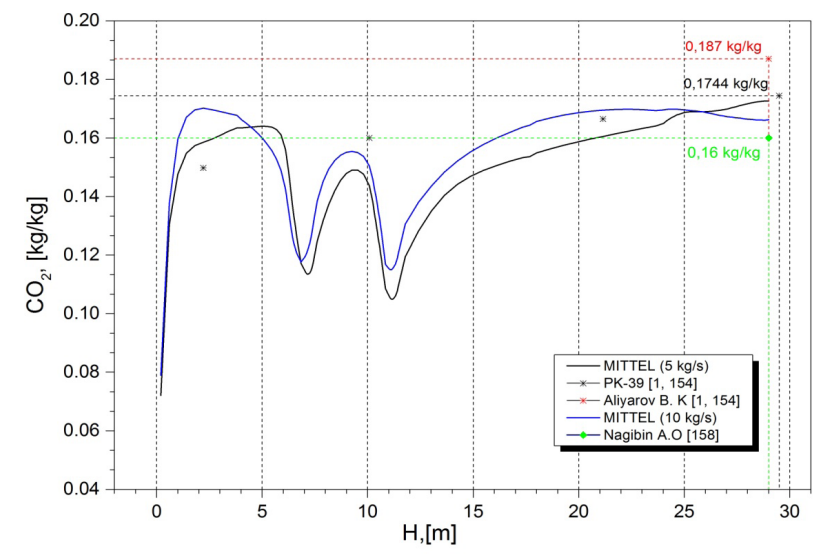

Figure 11 - distribution graph of mean values of carbon dioxide $\mathrm{CO}_{2}$ the height of the combustion chamber for different values of the mass flow of the additional air

By analyzing this chart you can see that in the location field of burners, and above them, the concentrations of carbon dioxide for the case when the flow of additional air through openings in the wall of the combustion chamber located opposite the burner units equal to $10 \mathrm{~kg} / \mathrm{s}$ higher than for the air flow $5 \mathrm{~kg} / \mathrm{s}$. 
Figure 12 shows the comparative distribution of the mean concentrations of $\mathrm{NO}_{2}$ at the height of the furnace. Analyzing the picture, you will notice that as you move to the exit of the combustion chamber, the concentration of nitrogen dioxide decreases. It is primarily associated with the destruction of nitrogen dioxide $\mathrm{NO}_{2}$ and its interaction with hydrocarbons, carbon, oxygen, etc., with the decrease of temperature in the upper layers of the gas mixture and of course a decrease in these areas, nitrate concentrations of fuel and oxidant, which is already chemically reacted in the bottom region of the burners.

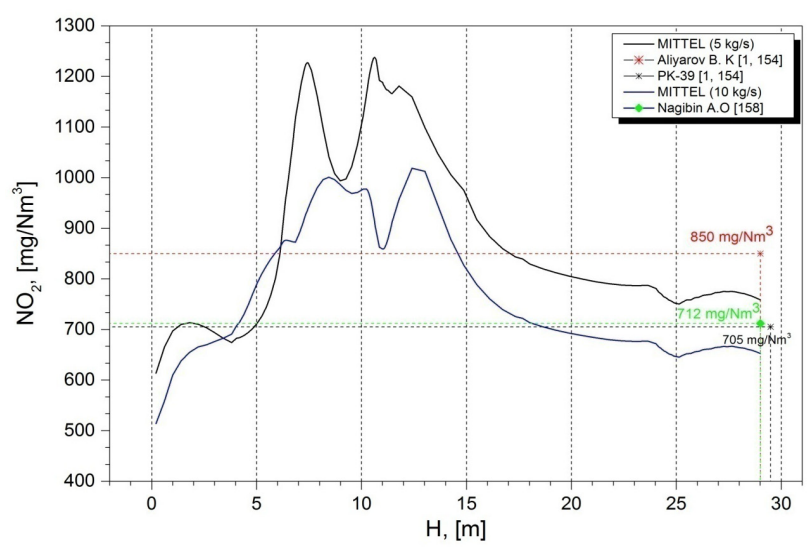

Figure 12 - Graph of the distribution of average values of nitrogen dioxide $\mathrm{NO}_{2}$ at the height of the furnace for different values of the mass flow of the additional air

\section{Conclusion}

By results of researches, we can draw the following conclusions

Computational experiments on the study of aerodynamic, thermal and concentration characteristics in combustion chamber of the boiler BKZ-420 Almaty TPP and the resulting velocity field, temperature, concentrations of harmful dust and gas emissions $\left(\mathrm{CO}, \mathrm{CO}_{2}, \mathrm{NO}_{2}\right)$ from the combustion of pulverized coal for different layout options holes and speed boost-extra air $(5 \mathrm{~kg} / \mathrm{s}$ and $10 \mathrm{~kg} / \mathrm{s})$.

Developed by optimum technology for burning high-ash fuel and energy and the best structural parameters of the combustion chamber of the boiler BKZ-420 Almaty TPP, which allows increasing the wear resistance of power and reducing the emission of harmful substances into the atmosphere. The proposed incineration of Ekibastuz coal lowers the temperature of the walls of the furnace located opposite to the burners at $3000 \square$, i.e., by $17.24 \%$, and reduces average concentrations of carbon monoxide at the outlet of the furnace by $15 \%$, carbon dioxide $\mathrm{CO}_{2}$ by $4.65 \%$ and nitrogen dioxide $\mathrm{NO}_{2}$ by $14 \%$.

\section{References}

1. Askarova A., Bolegenova S., Bekmukhamet A., Maximov Yu.V., Beketayeva M., Ospanova Sh. Gabitova Z.K. Investigation of turbulence characteristics of burning process of the solid fuel in BKZ 420 combustion chamber // WSEAS Transactions on Heat and Mass Transfer. -2014. Vol. 9. -P. 39-50.

2. Askarova A.S., Bekmukhamet A., Bolegenova S.A., Beketayeva M.T., Maximov Yu.V., Ospanova Sh.S., Gabitova Z.K. Numerical modeling of turbulence characteristics of burning process of the solid fuel in BKZ-420-140-7c combustion chamber // International Journal of Mechanics. - ISSN: 19984448. - 2014. - Vol. 8. - P. 112-122.

3. Askarova, A. S., Messerle, V. E., Ustimenko, A.B., Bolegenova, S. A., Maximov, V. Yu. Gabitova, Z. Kh. Numerical simulation of pulverized coal combustion in a power boiler furnace // High temperature. - 2015. - Vol. 53, issue 3. - P. 445-452.

4. Askarova, A. S., Bolegenova, S.A., Maximov, V.Y., Bekmukhamet, A, Beketayeva, M.T. Gabitova, ZK., etc. Computational method for investigation of solid fuel combustion in combustion chambers of a heat power plant // High temperature. - 2015. - Vol. 5, issue 5. - P. 751-757.

5. Askarova, A. S., Bolegenova, S.A., Maximov, V.Y., Bekmukhamet, A, Ospanova, S.S. Numerical research of aerodynamic characteristics of combustion chamber BKZ-75 mining thermal power station // Procedia Engineering. - 2012. - Vol.42. P. 1250-12-59.

6. Askarova A., Bekmukhamet A., Bolegenova S., Ospanova Sh., Bolegenova Symbat, Maximov V. Beketayeva M., Gabitova Z., Ergalieva A. 3D modeling of heat and mass transfer during combustion of solid fuel in BKZ-420-140-7c combustion chamber of Kazakhstan // Journal of Applied Fluid Mechanics. - 2016. - P. 699-709.

7. Askarova, A. S., Messerle V.E., Ustimenko A.B., Bolegenova, S.A., Bolegenova, S.A., Maximov, V.Y., Ergalieva A. Reduction of noxious substance emissions at the pulverized fuel combustion in the combustor of the BKZ-160 boiler of the Almaty heat electropower station using the "Overfire Air" technology // Thermophysics and aeromechanics. 2016. - Vol 23, issue 1. - P. 125-134.

8. Askarova, A. S., Bolegenova, S.A., Maximov, V.Y., Bekmukhamet, A, Beketayeva M., Gabitova Z. Control of Harmful Emissions Concentration into the 
Atmosphere of Megacities of Kazakhstan Republic // International Conference on Future Information Engineering (FIE2014), IERI Procedia. - Beijing, PEOPLES R CHINA. - 2014. -P. 252-258.

9. A. Askarova, S. Bolegenova, S. Bolegenova, V. Maximov, Manatbayev R, A. Yergaliyeva, Z. Gabitova, A. Maxutkhanova, Zh. Shortanbayeva, A. Boranbayeva, K. Berdikhan Application of 3D modelling for solving the problem of combustion coaldust flame // Bulgarian Chemical Communications. Special Issue E. - 2016. - P. 236-241.

10. A. Askarova, S. Bolegenova, N. Mazhrenova, Symbat Bolegenova, R. Manatbayev, I. Berezovskaya, V. Maximov, Sh. Ospanova, A. Nugymanova, Zh. Shortanbayeva 3D modelling of heat and mass transfer processes during the combustion of liquid fuel // Bulgarian Chemical Communications. - Special Issue E. - 2016. - P. 229-235.

11. A.S. Askarova, E. I. Heierle, S. A. Bolegenova, V. Ju. Maximov, S. A. Bolegenova, Manatbayev R, M. T. Beketaeva, A. B. Ergalieva CFD study of harmful substances production in coal-fired power plant of Kazakhstan // Bulgarian Chemical Communications. - Special Issue E. 2016. - P. 260-265.

12. A.S. Askarova, S.A. Bolegenova, Symbat Bolegenova, V.Yu. Maximov, R. Manatbayev, Zh.K. Shortanbayeva, A.M.Maksutkhanova, A.N.Aldiyarova, A.E.Boranbayeva Mathematical modeling of heat and mass transfer in the presence of physical-chemical processes // Bulgarian Chemical Communications. Special Issue E. - 2016. - P. 272-277.

13. M. Bugge, O. Skreiberg, N.E. Haugen, P. Carlsson, E. Houshfar, T. Lovas, Numerical simulations of staged biomass grate fired combustion with an emphasis on NOx emission, Energy Procedia. - Vol. 75. - 2015. - P.156-161.

14. W. Adamczyk, P. Kozolub, G. Wecel, A. Ryfa, Simulations of the PC boiler equipped with complex swirling burners, Int. J. Numer. Methods Heat Fluid Flow. - Vol. 25 (4). - 2014. - P.845-860.

15. B. Higgins, L. Yan, H. Gadalla, J. Meier, T. Fareid, G. Liu, M. Milewicz, A. Repczynski, M. Ryding, W. Blasiak, Biomass co-firing retrofit with ROFA for NOx reduction, Pol. J. Environ. Stud. Vol. 19 (6). - 2010. - P.1185-1197.

16. F. Lockwood, S. Rizvi, N. Shah, Comparative predictive experience of coal firing, Proc. Inst. Mech. Eng. C J. Mech. Eng. Sci. - Vol. 200 (23). - 1986. P.79-87.

17. M. Baum, P. Street, Predicting the combustion behavior of coal particles, Combust. Sci. Technol. Vol. 3 (5). - 1971. - P.231-243.

18. L. Alvarez, M. Gharebaghi, M. Pourkashanian, A. Williams, J. Riaza, C. Pevida, J. Pis, F. Rubiera, CFD modelling of oxy-coal combustion in an entrained flow reactor, Fuel Process. Technol. Vol. 92. - 2011. - P.1489-1497.

19. M. Cloke, E. Lester, A. Thompson, Combustion characteristics of coals using a drop-tube furnace, Fuel. - Vol. 81 (6). - 2002. - P.727-735.

20. H. Kruczek, M. Ostrycharczyk, M. Czerep, M. Baranowski, J. Zgra, Examinations of the process of hard coal and biomass blend combustion in OEA (oxygen enriched atmosphere), Energy. - Vol. 92. 2015. - P.40-46.

21. S. Du, W. Chen, J. Lucas, Pulverized coal burnout in blast furnace simulated by a drop tube furnace, Energy. - Vol. 35. - 2015. - P.576-581. 